\title{
Pragmatist Historiography in Unmodern Philosophy and Modern Philosophy
}

Phillip Deen

\section{CpenEdition}

\section{Journals}

Electronic version

URL: http://journals.openedition.org/ejpap/600

DOI: $10.4000 /$ ejpap.600

ISSN: 2036-4091

\section{Publisher}

Associazione Pragma

Electronic reference

Phillip Deen, «Pragmatist Historiography in Unmodern Philosophy and Modern Philosophy ", European Journal of Pragmatism and American Philosophy [Online], V-1 | 2013, Online since 16 July 2013, connection on 20 April 2019. URL : http://journals.openedition.org/ejpap/600 ; DOI : 10.4000/ ejpap.600

This text was automatically generated on 20 April 2019.

\section{c) $(7) \Theta$}

Author retains copyright and grants the European Journal of Pragmatism and American Philosophy right of first publication with the work simultaneously licensed under a Creative Commons AttributionNonCommercial-NoDerivatives 4.0 International License. 


\title{
Pragmatist Historiography in Unmodern Philosophy and Modern Philosophy
}

\author{
Phillip Deen
}

1 It is tempting to dismiss the first half of Unmodern Philosophy and Modern Philosophy. At first blush, it would not seem to be essential to Dewey's foremost concern to provide a naturalized account of knowing that avoids the hoary philosophical dualisms of body/ mind, thing/person, material/ideal, and practical/theoretical. The load-bearing chapters would seem to be in the latter philosophical half in which he takes on the task of developing a positive account rather than the early historical half in which he explains how the philosophical tradition came to be in this unfortunate position. To those familiar with Reconstruction in Philosophy and The Quest for Certainty, the account of the rise of epistemology as the core of western philosophy may seem familiar and, therefore, unnecessary. Though Dewey delves deeper into medieval and modern figures than in his other historical accounts, the outline of the historical account is largely the same. Further, you could also accuse Dewey have written a poor history. As a work of contemporary intellectual history, it suffers. It is both too broad and too narrow, focusing on a particular philosophical problem while also being broad and unrestrained in its summaries of various eras. And there is little-to-none of the rigorous citation or reliance on statistics that mark much of today's historical writing. As tempting as it might be, I believe it would be a great error to ignore the historical half of Dewey's philosophical history of modernity. In Unmodern Philosophy and Modern Philosophy, the first half does not report and the second half argue. Rather, the historical account is a philosophical argument.

2 To make my case, I will turn to the broader topic of pragmatist historiography - the principles, theory and history of historical writing. "History" has various meanings, including: 1) the actual events of the past insofar as they are connected to humanity; 2) philosophy of history, which presents an account of the rational ordering of history or its 
underlying rationality as in Hegel. This includes a periodization of the events of the past and an account of the mechanism by which those events proceed; and 3) the discipline of history, including principles governing how one is to study and recount the actual events. There are threads of each in Dewey's vast corpus. Within his work and that of other pragmatists, one can find intimations of a broader theory of how human events proceed, their mechanisms, and what sort of underlying rationality (if any) is being expressed. However, the concern here is with the discipline of history; that is, with how to study and recount historical events.

3 I argue here that Dewey's historical account of the unfortunate rise of epistemology is an example of a broader pragmatist theory of the discipline of history. This theory of history holds that value-free, objective reporting of past events is ultimately impossible. Rather, historical writing is inevitably a history of the present and shot through with our concerns and judgment. Once I have provided a sketch of pragmatist historiography, both in Dewey's work and others', we can return to see how this framework informs Unmodern Philosophy.

\section{米}

4 Cushing Strout detailed what he called the "pragmatic revolt in American history" by authors such as Carl Becker and Charles Beard (Strout 1958). Close to the heart of this revolution was a rejection of pure objectivity in the field of history. The earlier 'New History', including Frederick Jackson Turner, James Harvey Robinson, and Harry Elmer Barnes, directly challenged the notion that history is merely the discovery and reportage of what happened. History is not and can not be the recounting of facts by unbiased spectators, as historians are inevitably concerned agents within history. Turner asserted that "each age writes the history of the past anew with reference to the conditions uppermost in its own time" (Turner 1939: 32). The purpose of history is then not to write what happened from some Archimedean vantage point, but to understand how the present, with all of its continuities, divisions, and values, came about. It is not a statement of past facts, but a genetic account of the present. ${ }^{1}$

5 Further, the New Historians and their heirs understood their work as part of the ongoing liberation from past superstition by scientific intelligence. History is a value-laden endeavor by which the present is freed from the errors of the past. Hence, this is an account of history that is scientific in temper, but one also suspicious of positivist historians' claim to be value-free in their recounting of the past. In the words of James Kloppenberg, himself bo th a pragmatist historian and historian of pragmatism, "Becker challenged the pretensions of 'scientific' history and argued instead that history consists of a set of stories that enable ordinary people to locate themselves in the sea of time. Becker conceived of knowledge, and of historical writing, as the product of pragmatic communities of discourse" (2004: 206; see also Kloppenberg 1987). They understood history to be a scientific discipline, but also humanistic (Strout 1958: 21-29).

This rejection of the spectatorial position resonates with Dewey's own critique of the spectator theory of knowledge, but these historians were not necessarily directly influenced. No substantial connection between pragmatism and history appears to exist until the interwar period. Classical pragmatist philosophers rarely wrote on the discipline of history, with the most substantial exception being Dewey's short selection on historical judgments in Logic: The Theory of Inquiry (Dewey 1938: 230-43). Similarly, the historians did 
not claim pragmatism as a direct influence. Beard was a close friend of Dewey's and Becker once referenced pragmatism in his work, but neither presented themselves as devotees.

However, there does seem to be a shared temper between pragmatism and certain antiobjectivist strands of American historians. Becker wrote, "John Dewey's books I find hard to understand, but his ideas, coming to me from other writers, have confirmed a native tendency to pragmatic theory" (Novick 1988: 151). They shared a common sensibility reflecting a faith in scientific method wedded to a suspicion of the quest for certain knowledge. "Pragmatism's crusade against the worship of facts, its skepticism about claims of objectivity, its consistent reluctance to accept a hard-and-fast fact-value distinction, its emphasis on change and flux, on the human and social elements in knowledge, and the stress on the practical consequences of knowledge" were shared by the anti-objectivist historians (Novick 1988: 153).

8 Correspondingly, Dewey shared his contemporary historian's rejection of pure objectivity in historical writing. Echoing James' belief that "experience" is a double-barreled word, Dewey held that "history" has a dual meaning:

History is that which happened in the past and it is the intellectual reconstruction of these happenings at a subsequent time. The notion that historical inquiry simply reinstates the events that once happened 'as they actually happened' is incredibly naïve. It is a valuable methodological canon when interpreted as a warning to avoid prejudice, to struggle for the greatest possible amount of objectivity and impartiality, and as an exhortation to exercise caution and skepticism in determining the authenticity of material presented as potential data. In any other sense, it is meaningless. (1938: 236)

Objectivity is then a set of methodological principles bearing on the conduct of historians, a regulative ideal that is not actually attainable.

If historical inquiry is not the reporting of objective facts by subject-less inquirers, then how does it proceed? Why concern oneself with what happened in the past at all? Though Dewey was sharply critical of the philosophical tradition tracing to the Greeks, it is wrong to conclude that Dewey believed it was possible to separate oneself from it. Cruder criticisms of pragmatism take it to be a blithe orientation to the future with no regard for the past. However, Dewey and other pragmatists continually strove to wed their prospective and practical interests to historical-genetic analysis. Criticism of a tradition requires engagement with and through it. The purpose of such engagement with the past is not to put it in a museum exhibit as proof of our ability to catch it, or to hold it up as a treasure to be admired, but to see how study of history is instrumental to a desirable future. Put simply, the practical, future oriented interest is reconciled to the historical, genetic one because historical inquiries are useful.

11 Much like the natural scientist or the engineer, the historian collects data and proposes hypotheses that are tested in the course of future experimentation. It is not enough to collect information about past events, but they must also present an interpretation of those events which sets them in relation to one another and to the present. They are to be "carried forward into the future by reasoning, then tested and validated in practice, and used, it may be, by what might be called social engineering as a method of controlling the social environment" (Blau 1960: 96). Judgments about historical events are then testable hypothetical reconstructions. "The writing of history is an instance of judgment as a resolution through inquiry of a problematic situation" (Dewey 1938: 232). The methods by which beliefs about history are warranted are no different in principle than 
those of science, though historical and scientific inquiries have different subject matters and, thus, different tests.

To cite Dewey directly, "All historical construction is necessarily selective" (1938: 234). It is selective in at least three ways. First, previous generations selected what would be recorded and what would not. Second, folk memory chose what would be preserved in their traditions and carry on to the present day for historians to observe. Third, present historians select out what is relevant to their inquiries and what is not. Data is discriminated from mere events when it is believed that it is relevant to the concern at hand. "Apart from connection with some problem, they are like materials of brick, stone and wood that a man might gather together who is intending to build a house but before he has made a plan for building it" (Dewey 1938: 232). Clearly, the historian does not study everything simultaneously, but instead makes judgments that some events were more central than others. Whether a specific event lies at the center or the periphery is dependent upon the interpretive framework and practical concerns of the historian.

The obvious and immediate objection is that historical judgments are true or false insofar as they correspond to events that have already happened and thereby beyond our control to make true. Whether Lee Harvey Oswald shot President John F. Kennedy is a matter for the past and it is not up to us to say whether the proposition 'Lee Harvey Oswald shot President John F. Kennedy' is true. Historical inquiries may discover fixed facts, but it does not transform them into facts. Burleigh Wilkins, despite presenting a responsible account of Dewey's theory of historical inquiry, accused him irresponsibly of allowing the historians to believe whatever they desired by strategic selection of facts to suit their desired outcomes: "What are these in effect but alibis for the historian who wishes to prejudge, or misjudge, the past? [...] I fail to see that history can fulfill any function, except for those who delight in playing tricks upon the dead" (Burleigh 1959: 885-84).

It is important to note that rejection of objectivity and the recognition of selective interest entail neither relativism nor skepticism. Ultimately, Burleigh's argument rests on the assumptions that the true historian discovers fixed events and that, once we accept the presence of practical interest in historical inquiry, one has abandoned the search for truth. The first assumption is rejected by the pragmatist for the reasons already given and Burleigh offered no argument in response, except those that beg the question.

The second assumption is rejected by the pragmatist historian because of his conception of truth as a regulative ideal that places limits on the desires of the individual historian. Faith in scientific method entails a hope for consensus and the eventual reconstruction of a problematic situation, while never forgetting that all answers are revisable in light of further experience. To repeat with a sigh what pragmatists have been saying for years, the pragmatist theory of truth does not reduce truth to what pleases the individual. It may seem contradictory to assert both (a) historical judgments reflect selection of data, proposal of hypotheses, and tests all motivated by our practical interests, and (b) whether Lee Harvey Oswald shot JFK is not a matter of whether one desires it to be true. However, there is a way through. The pragmatist holds that truth is something that happens to a proposition through the process of experimentation. There is no sense of truth which does not include a process of practically connecting concepts to perceptual experience. It simply does not make sense to assert that something is true but has no continuity with our own experience. To tweak Peirce's example, it is like asserting that an object that no one will ever, or could ever, encounter is hard. The proposition has no meaning. The assertion that JFK was or was not shot, when radically separated from any possible 
inquirer in the present, collapses. It has no meaning for us, and that is the only meaning there is. We may assume the position of some Objective observer, but this God-like position is either some actual present observer(s) or some imagined future observer(s).

Further, as noted, histories are selective. Some events are picked out as data while others are not on the expectation that those selected events will prove worthwhile in ongoing inquiry. If one were to write a history of the American presidency immediately prior to JFK's assassination, it would have a different data set from that written immediately after. Lee Harvey Oswald would still have led the life he did prior to the assassination, but whether his life is counted as data for our inquiry, and the significance of events in his life, would take on radically new meaning. The meaning of the past, and the truth of historical judgments, are mutually determined as time moves forward. Historical writing dialectically relates the meanings of the past and the present, changing both. In Joseph Blau's eloquent words, "each present has a new past" (1960: 99).

For the pragmatist historian historical inquiry is then necessarily value-laden and selective rather than Objective and value-free. This does not take place in a vacuum. Behind historians and their inquiries is a broader social context that directs why they inquire. "For historical inquiry is an affair (1) of selection and arrangement, and (2) is controlled by the dominant problems and conceptions of the culture of the period in which it is written" (Dewey 1938: 236). The historian does not work from outside of culture, but from within one shot-through with cultural problems and inherited cultural frameworks. Historians' problems are not exclusively their own.

There is no history except in terms of movement toward some outcome, something taken as an issue, whether it be the Rise and the Fall of the Roman Empire, Negro Slavery in the United States, the Polish Question, the Industrial Revolution or Land Tenure. [...] The urgency of the social problems which are now developing out of the forces of industrial production and distribution is the source of a new interest in history from the economic point of view. When current problems seem dominantly political, the political aspect of history is uppermost. (Dewey 1938: 237)

Like the philosopher or the social scientist, the historian is counter-intuitively concerned with the present. ${ }^{2}$

Ultimately, the historian is concerned with the future as well, to address the underlying cultural contradictions and to resolve the problems of the present. The present reaches both backward and forward. "The selection of the end or outcome marks an interest and the interest reaches into the future" (Dewey 1938: 237). And the discipline of history is itself an intervention. "The writing of history is itself an historical event. It is something which happens and which in its occurrence has existential consequences" (Dewy 1938: 237). The historian, however slightly, redirects history.

In sum, Dewey and many of Dewey's contemporary historians abandoned the model of the historian as reporter of mere happenings. Rather, history is a practically engaged, value-laden practice that arises against its background cultural tensions and assumptions and is inevitably oriented toward a desired future. It identifies problems and hopes to resolve them by proposing and testing hypotheses / interpretive frameworks.

\section{米}

21 Dewey's associate George Boas provided a survey of the problems an instrumentalist history of philosophy would have to address: "(1) the specific end which the philosophical 
solution was devised to attain; (2) the possibility of a given solution's being used for a variety of ends; (3) the survival of obsolete questions and answers; (4) the rise of the terminal value of obsolescent ideas" (Boas 1950: 87). Boas bemoaned the fact that no such instrumentalist history of philosophy had not been written as of 1950. Arguably, it has still not been written. However, if these are the tasks of an instrumentalist history of philosophy, then it is clear that Dewey was attempting to write one in Unmodern Philosophy and Modern Philosophy. Here, Dewey tried to explain how it is that philosophers developed solutions to contextualized problems and the unfortunate ways that those solutions have taken on a life of their own and continue to serve ends alien at the time of their creation. To those who have read Unmodern Philosophy and Modern Philosophy, there is perhaps no need to explain further. What I have written so far may obviously inform the central arguments of that text. However, for the sake of clarification, and for those who are not yet familiar with Unmodern Philosophy, let us make the connections clear.

If historical writing is necessarily a selective enterprise governed by a practical concern to resolve present difficulties, then we must identify what concern governs Unmodern Philosophy. Most broadly, it is the same that animates Dewey's thought generally; that is, the desire to extend the operation of intelligence to morals - the realms of aesthetic appreciation, of right conduct, fulfilling social life, and so on. Therefore, his various histories of philosophy are going to be concerned foremost not in recounting events, or providing a sweeping panorama or various gestalten, but in showing the frequently frustrated work of intelligence. John Herman Randall, perhaps the best commentator on Dewey's historicism, stated, "Where Dewey approaches most closely to the narration of a history - as in the Reconstruction in Philosophy - it is in following the thread of the development of method. For him, it is method rather than vision that is fundamental in the history of philosophy, $t$ hat reflective and critical method that aims to reorganize and reconstruct beliefs" (1939: 78-79). ${ }^{3}$ Similarly, and with specific reference to Dewey's writings on the Greeks, who occupy a central place in Dewey's historical account, Frederick Anderson wrote, "most of John Dewey's significant commentary on ancient philosophy occurs within argument for some special phase of his own theory of inquiry. The indication, I believe, is that, in Dewey's eyes, the study of Greek philosophy should not be thought of primarily as the occupation of a special academic task force, but a continuing reinterpretation that is of general importance within contemporary philosophy" (1967: 86). ${ }^{4}$

Unmodern Philosophy takes method as its central concern, and not only in the latter conceptual half. The first three chapters engage in a roughly anthropological account of the origin of Western philosophy in the conflicts within and between cultures. Philosophy in any era is a reflective response to concrete social conditions. At the origin of philosophy, increased commerce and contact between cultures called into the question the narratives that societies tell to make sense of life. Conflicting narratives produced the need to invent the very notion of a fundamental object of thought, and correspondingly, the notion of a method of thinking. Agrarian and industrial models of Nature, corresponding to basic Greek ways of life, were proposed to make sense of lived conflicts.

These incompatible narratives (and others) then necessitated a new problematization: "How is rational discourse possible?" (36). It is the discovery of logical method itself. Similarly, it is the identification of a proper object for thought - Nature itself. In Dewey's narrative, Plato's search for method and its object was never far from his moral concern to develop a legislative art that will overcome the disintegration of Athenian culture and 
recapture their prior easy harmony. Sadly, with Aristotle, the limitations of Greek logic themselves reflective of Greek social contradictions and language and of the poor state of natural science - prevented a proper theory of inquiry and its object from being developed. "The state of invention and technology rendered any adequate experimental analysis of nature impossible. The best that can be done under such conditions is to organize and define critically what is already believed, and the body of existing beliefs in absence of any technique of systematic discovery had of necessity developed accidentally and causally" (50). Aristotle reached the heights of what was possible, given the problems and methods available to an ancient Greek, but his organum was critically flawed. It encompassed a logic of discovery, but not one of experimentation. What is worse, Plato's essential connection between method and morals was lost as the theoretical and the practical were severed. As cultural conditions changed, the problematizations shifted as well $5 .{ }^{5}$ With the Medievals, the problem of method and its object was supernaturalized into one of the relation between levels of reality. With the moderns, 'How is rational discourse possible?' became 'Is knowledge possible?' Corresponding to new problematizations came new objects: for the Medievals, it was the God as articulated in the synthesizing institution of the Church and, for the moderns, it is the Object which is somehow other than the Subject yet somehow potentially an object of knowledge.

Dewey's history of philosophy then periodizes time and, like other historians', it contains an agenda. Periodizations make claims about history's pivotal moments and arcs, and predict where it is headed, for good or ill. Rather than a Christian two-era periodization, in which time is divided into a period of darkness and another of redemption following the appearance of Christ, or a Renaissance three-era periodization in which time is divided into Greek heights, a Medieval Dark Age, and then a time of classical rebirth, Dewey offers a four-era interpretive model. Like the Renaissance Humanists, he sees a height of a limited humanistic naturalism, a fallow period (while also recognizing the Church as a successful synthesis of its culture), and the promise of a new humanistic naturalism with the advent of modern science. However, the new naturalism has so far failed. ${ }^{6}$

27 For Dewey, modernity is still a project and he combined a strong sense of modernity's newness with frustration at its failure to realize. In writing Unmodern Philosophy, Dewey repeatedly returned to Matthew Arnold's description of modernity as "Wandering between two worlds, one dead / The other powerless to be born" and we (un)moderns "have a sense that their system is not their own creation, and that it by no means corresponds exactly with the wants of their actual life; that, for them, it is customary, not rational. The awakening of this sense is the awakening of the modern spirit" (92). ${ }^{7}$ Hence, we come to the pragmatist historian's concern for the future.

The next period has not yet happened. We do not have a naturalized account of knowing, but epistemology. The latter reflects the problematization originated by the Greeks and modified by the Medievals and (Un)moderns, but never overcome. Dewey's history of philosophy is then not oriented to recount simply what happened, but to stage a critical intervention into that history, to introduce a change in existential conditions going forward. By producing a selective narrative, he is hoping to provoke a certain interpretive model in the reader and thereby clear the way for a better future. Ultimately, Dewey is trying to recover the connection between method and morals that he found in Plato, though certainly not the same method, nor the same morals. As cited above, the 
historian's selective interest is futural. Dewey is not writing a critical history of philosophy out of a pure concern to report the events, but because it makes way for a naturalistic culture of inquiry, a democratic community that attends to experience. on thirty issues they took to be central to the discipline (Bourget and Chalmers forthcoming). The answers they received are not as important as the questions they asked and who they asked them of. Of those thirty questions, one was on aesthetics, one on philosophy of religion, three or four were on meta-ethics (depending on whether one considers the issue of free will to be primarily an ethical concern), two were on ethics, and one on politics. The twenty-one remaining questions regarded issues of epistemology and metaphysics. Perversely, there were more questions regarding the significance of teleporters and zombies than either politics, God, or aesthetics. And of the two ethics questions, one regarded whether one should reroute the trolley in the famed thought experiment. To their credit, Bourget and Chalmers acknowledge that their survey sample was drawn primarily from analytic philosophers at elite, mainstream universities with Ph.D. programs. But perhaps this admission is itself an unintentional condemnation of the state of the dominant anglophilic conversation.

Dewey repeatedly complained that epistemology-centered philosophy addresses the problems of philosophers rather than the problems of men. Unless English-speaking society truly considers the questions of faith, goodness, justice and beauty to run far second to those of knowledge and Being (and zombies and teleporters), then Dewey's complaint would appear to be true today. And insofar as those questions focus on the very possibility of knowledge of existence rather than how to know and exist well, then he was all the more correct in his analysis. Dewey's Unmodern Philosophy and Modern Philosophy provides a critical genealogy that is perhaps familiar to those who know his other works, but it is still needed despite its familiarity. Dewey's history of western philosophy looks to the future, toward the democratic culture that is synonymous with a culture of inquiry. It is a prospective history of philosophy that clears the way for a naturalize account of knowing that, Dewey hoped, would produce a richer and more humane community.

\section{BIBLIOGRAPHY}

ANDERSON F. M., (1967), “Dewey's Experiment with Greek Philosophy,” International Philosophical Quarterly, 7, 1.

AUXIER R., (1990), “Dewey on Religion and History," Southwest Philosophy Review, 6, 1.

AUXIER R., (2002), "Foucault, Dewey, and the History of the Present," Journal of Speculative

Philosophy, 16, 2.

European Journal of Pragmatism and American Philosophy, V-1 | 2013 
BLAU J., (1960), “John Dewey's Theory of History,” The Journal of Philosophy, 57, 3.

BOAS G., (1950), "Instrumentalism and the History of Philosophy," in John Dewey: Philosopher of Science and Freedom, ed. by Sidney Hook, New York, Dial Press.

BOURGet D., \& D. ChalmERs, (forthcoming), “What Do Philosophers Believe?," Philosophical Studies. DEWEY J., (1938), Logic: The Theory of Inquiry, in The Collected Works of John Dewey, Carbondale, Southern Illinois University Press.

DEWEY J., (2012), Unmodern Philosophy and Modern Philosophy, ed. by P. Deen, Carbondale, Southern Illinois University Press.

KLOPPENBERG J., (1987), “Morton White's Social Thought in America," Reviews in American History, $15,3$.

KLOPPEnBeRg J., (2004), "Pragmatism and the Practice of History: From Turner and DuBois to Today," Metaphilosophy, 35, 1.

KOOPMAN C., (2010), "Historicism in Pragmatism: Lessons in Historiography and Philosophy," Metaphilosophy, $41,5$.

KoOPMAN C., (2011), "Genealogical Pragmatism: How History Matters for Foucault and Dewey," Journal of the Philosophy of History, 5, 3.

Novick P., (1988), That Noble Dream: The "Objectivity Question" and the American Historical Profession, New York, Cambridge University Press.

RANDALL J. H., (1939), “Dewey's Interpretation of the History of Philosophy," in The Philosophy of John Dewey, ed. by P. A. Schlipp and L. E. Hahn, LaSalle, Open Court Press.

RANDALL J. H., (1958), Nature and Historical Experience, New York, Columbia University Press.

RANDALl J. H., (1963), How Philosophy Uses its Past, New York, Columbia University Press.

STROUT C., (1958), The Pragmatic Revolt in American History: Carl Becker and Charles Beard, New Haven, Yale University Press.

TURNER F. J., (1939), The Early Writings of Frederick Jackson Turner, Madison, University of Wisconsin Press.

WILKINS B. T., (1959), "Pragmatism as a Theory of Historical Knowledge: John Dewey on the Nature of Historical Inquiry," The American Historical Review, 64, 4.

\section{NOTES}

1. For an analysis of Dewey and Foucault on histories of the present, and of a possible Deweyan influence on Foucault, see Auxier 2002. For more by Auxier on Dewey, religion and history, see Auxier 1990.

2. In an impressively foreshadowing passage immediately after the one just quoted, Dewey then turns to those who write history out of their concern for climatic changes.

3. Randall's work has faded from the conversation, but he deserves a rediscovery. For more from Randall directly relevant to the present article, see (Randall 1958, 3-13, 35, 39-44, 56-61; and Randall 1963, esp. 13-27, 79).

4. My thanks to Albert Randall Spencer for making me aware of this text.

5. "Problematizations" is knowingly taken from the thought of Michel Foucault. It is no coincidence that the intersection between Dewey and Foucault has appeared in recent writings 
on pragmatist historicism. Randall Auxier's work was mentioned in a previous footnote. I would highlight Colin Koopman's work on Dewey, Foucault and problematization (Koopman 2010, and Koopman 2011).

6. Had I the space in this article, I would investigate the possibility of a parallel genealogy of critique in Dewey's history of philosophy. Parallel to Foucault's extensive genealogy of disciplinary power/governmentality, he also wrote a short account of the rise of critical reason/ Enlightenment. Given Dewey's all too brief mention of the progressive element of modern philosophy, the possibility of a similar genealogy of critique is intriguing (170-74).

7. As editor of the manuscripts, I can testify that Dewey typed this entire passage out in draft after draft (as well as Malikowski's definition of culture).

\section{AUTHOR}

\section{PHILLIP DEEN}

University of New Hampshire

phillip.deen[at]unh.edu 